\title{
Effects of Students' Home Environment, Tools, and Technology Used on Online Learning Experience in a Civil Engineering Program
}

\author{
Tahar Ayadat, Mohammad Ali Khasawneh, Saidur Rahman Chowdhury, Mohammed Nayeemuddin, \\ Danish Ahmed, and Andi Asiz
}

\begin{abstract}
The COVID-19 pandemic has caused major disruptions in every sector of human activity around the world. The education sector is no exception. Due to physical restrictions in accessing campus infrastructures, students and instructors at academic institutions have forcibly adapted to the new norm of virtual learning with mixed expectations and outcomes. There have been several studies conducted by educational practitioners since the pandemic began, which mostly focused on how academic constituents quickly adapt to virtual learning in a general sense. The main objective of this study is to examine the effects of virtual learning infrastructure and environment on student learning, specific to the civil engineering program at Prince Mohammad Bin Fahd University (PMU). A survey was distributed to civil engineering students at PMU at the end of the fall 2020 term to gather perceptions about virtual learning and check the adequacy of online learning tools and associated environments. Student performance during virtual learning in terms of grade achievement was also investigated and compared with a normal situation. In general, it was found that students are satisfied with the current technology used to facilitate virtual learning. The anticipated outcomes of this study, including online technology readiness, curriculum adjustment, and teaching styles or methods, are to be used for virtual learning improvement should the current pandemic restriction extend to the end of the 2020-21 academic year and possibly far beyond.
\end{abstract}

Index Terms-COVID-19 restrictions, engineering education, equipment used, online learning, student environment, student perception.

\section{INTRODUCTION}

The COVID-19 pandemic has caused major disruptions in every sector of human activity around the world, and the education sector is no exception. With short notice, around the middle of the 2020 spring semester, most teaching and learning practices at universities in Saudi Arabia migrated from traditional in-person to virtual learning modalities due to full or partial campus closures [1]. This posed significant challenges to the universities and their professors, given that the course modules and their respective teaching activities

Manuscript received January 21, 2021; revised May 8, 2021.

The authors are with Prince Mohammad Bin Fahd University (PMU), Al Khobar, Saudi Arabia (e-mail: tayadat@pmu.edu.sa, mkhasawneh@pmu.edu.sa, schowdhury1@pmu.edu.sa, mnayeemuddin@pmu.edu.sa,dahmed@pmu.edu.sa, aasiz@pmu.edu.sa). were mostly originally designed for traditional face-to-face instruction. Fortunately, virtual teaching aids have been available since so-called online learning was introduced more than 20 years ago, either as an integrated tool within a university learning management system or as commercial ready-to-use tools. In this paper, the term "virtual learning" is used to reduce misconceptions about the differences between online and distance learning. The virtual learning modality, which is a term sometimes used interchangeably with online, distance, or remote learning, emphasizes the use of the internet as a major facilitator for communication, regardless of learning times and places [2]-[4]. At Prince Mohammad Bin Fahd University (PMU), virtual learning has been conducted using the existing online teaching platform Blackboard and its module Collaborate Ultra. This teaching platform was frequently used in the Saudi higher education sector even during normal times [5]. PMU is a private university located in the eastern province of Saudi Arabia. It was established in 2006 with four colleges (engineering, computer, business, and core) distributed over 15 programs. English is used as the medium of instruction in teaching and learning. As of the 2019-20 academic year, the total number of PMU students across the four colleges was 4,233, with 224 members of the teaching staff. The total number of civil engineering students is 138, with seven members of the teaching staff. All engineering programs at PMU, including civil engineering, are accredited by the Accreditation Board for Engineering and Technology (ABET).

Prior to the pandemic, PMU teaching staff regularly used Blackboard for posting most course materials, while retaining key learning communication in face-to-face instruction. Some teaching staff also used Blackboard further to facilitate online group discussion and administer online reviews and assessments. However, the majority of the teaching staff had never utilized Blackboard Collaborate Ultra during normal times due to no urgency to move face-to-face learning to remote or distance learning modes. In principle, Collaborate Ultra is a video-based conferencing tool that incorporates basic Blackboard teaching features, including file sharing, online group discussion, online review and assessment, and virtual interactive whiteboard. Due to previous experience in operating Blackboard, the sudden migration process from in-person to virtual leaning at PMU went smoothly, with only minor iterations in getting familiar with the electronic teaching communication tools. Additional resources for virtual learning using commercially available platforms (e.g., Zoom, Microsoft Teams, YouTube) were suggested for students if Collaborate Ultra did not provide 
needed features.

Since the end of the spring 2020 term, numerous studies have been conducted by academic institutions about the impacts of COVID-19 restrictions. Most of the studies have utilized and analyzed some data produced during virtual teaching and learning, such as observations based on student or faculty satisfaction surveys, academic institution responses, and learning outcomes assessment analyses [6]-[11]. There have been mixed perceptions of the impacts of the virtual modality on teaching and learning performance, particularly for those having a first-time experience. The majority of the studies reported that students and faculty faced few challenges in terms of infrastructure readiness, curriculum adjustment, flexibility in grading and assessment, and negative perceptions of online learning [12]-[17]. However, having been forced to experience virtual learning, educational practitioners have identified opportunities to improve the overall learning practice by integrating a conventional curriculum into modern online technologies in the forms of e-learning or blended (mixed) learning [18]-[24].

Similar study of virtual learning during the COVID-19 pandemic was conducted by Romaniuk and Lukasiewicz-Wieleba (2020) [6] who collected and analyzed data based on survey distributed to students from faculties of pedagogy, special education, psychology, and sociology at The Maria Grzegorzewska University. Some of their questionnaires asked students about information technology (IT) competencies, computer and internet connection reliability, and their overall impacts on virtual learning. They concluded that readiness of faculty and students dealing with IT compounded with attitude toward virtual learning were found to be major issue for students achieving intended learning outcomes. As will be discussed later in this paper, in addition to the similar issues experienced by social science-based students, civil engineering students whose learning is partly relied on experimentation in laboratory have unique issue in term of experiencing hand on laboratory exercises during virtual learning.

The main objective of this study was to examine the effects of the virtual learning infrastructure and environment on student learning, based on a survey conducted among civil engineering students at PMU at the end of the fall 2020 term. The outcomes of this study are to be used for virtual learning improvement should the current pandemic restrictions be extended to the end of the 2020-21 academic year and possibly further.

\section{Methodology}

A descriptive survey was conducted in the department of civil engineering (CE) at PMU in order to assess the effect of students' home environments, tools, and technologies used on the online learning experience of CE students. The survey systematically evaluated the perceptions and judgments of the respondents about their virtual learning experience.

Before the development of the questionnaire the objective of the survey, the research questions, the target population, and the sampling and data collection procedures were first identified. Then a reliable and valid survey instrument was prepared and approved by appropriate expert. A pilot test was conducted before administering the survey and collecting the data.

Data from the study were assessed from the randomly sampled responses generated by nearly 200 undergraduate students in the PMU CE bachelor of science degree program. The data were collected through a descriptive questionnaire prepared by the faculty of the department. The items of the survey questionnaire were adopted for the purpose of investigating the different elements that might affect the virtual learning outcomes or experiences of the students. The items on the questionnaire were arranged in sequence in three categories (Table A1 of Appendix A). Category I, which grouped 10 basic questions noted as basic questions (Q1 to Q10), elicited the personnel profile of the respondents with respect to the environment and equipment used during their online learning. Category II examined the convenience of virtual learning compared to in-class learning. This part was composed of five questions (Q12 to Q16) that were noted as general questions. Category III arranged five specific questions (Q17 to Q21). This part investigated the convenience of and challenges in conducting online laboratory experimentation, performing computer modeling simulation exercises, field trips and technical workshops, and performing engineering design exercises. Questions asking for student comments regarding the major benefits, major drawbacks, and suggestions for improvement were also provided in the survey (Q11 and Q22).

The questionnaire was elucidated and validated prior to its distribution. The survey was validate in order to consolidate its dependability. The survey's face value was established by experts. Furthermore, the survey was pilot tested on a subset of survey participants. The objectives and significance of the study were then discussed with the CE students, and their voluntary participation was sought. To ensure the confidentiality of the survey, the questionnaire was administrated to students through the American Society of Civil Engineers (ASCE) Civil Engineering Club. The distribution of the questionnaire lasted for two weeks, after which the tabulation and analysis of the data were carried out. To analyze the data, descriptive statistics were used, including mean, mode, standard deviation, coefficient of variation, and percentage distribution, to examine the different variables of the study. The data of the collected responses were cleaned through a spreadsheet. The interpretation of the variables and level of satisfaction were rated on a scale of 1 to 5 , where $1=$ strongly disagree and $5=$ strongly agree.

It is worthy to note that, certainly, using multiple sources of data and research methods to understand phenomena yields many benefits. However, the descriptive research model used in this study is considered conclusive in nature due to its quantitative nature. Also, it is considered as one of the most reliable and prevalent research method. It is more appropriate to use this type of research model to better define an opinion, attitude, or behaviour held by a group of people on a given subject. The participants sample is adequate, valuable and representative. Furthermore, due to the current COVID situation, the methods of acquiring data, storing data, and processing data become not easier and costly. 


\section{RESUlTS AND DisCUSSION}

As discussed above, the main purpose of this study was to evaluate or assess the effect of students' environment and equipment used on their virtual learning experience. The survey was conducted to continuously improve the effectiveness of virtual online learning, recognizing that the assessment of how well our students have received their online learning is an important consideration in the evaluation of such learning methods. Addressing the shortcomings and suggestions provided by students will be applied to improve the virtual teaching modality at PMU should the current pandemic situation continue indefinitely or in the case of any similar situation in the future.

As mentioned previously, the results of the survey (i.e., the students' responses) were tabulated and analyzed. In order to more clearly perceive and quantify the answers and the appreciations of the students, the analysis was conducted as follows: first, the different categories of questions were analyzed separately. Then, the questions from categories II and III were examined in comparison to each question from category I.

Fig. 1 presents the students' responses (in percentages) to the basic questions. It is clear from Fig. 1 that $95 \%$ of the students had access to a device for learning online, and $71 \%$ had high-speed internet at home. Almost all students (92\%) were using a laptop for their distance learning online. At home, $90 \%$ of the students were studying in a peaceful to occasionally disturbed environment. Furthermore, many families were supportive of the virtual learning, with $86 \%$ of students replying that their families were extremely helpful to moderately helpful. Concerning the cooperation between students, $43 \%$ of students declared that their coworkers were extremely to very helpful, while $39 \%$ indicated that their coworkers were moderately helpful. Slightly more than half (53\%) of the students answered that they did not face any obstacles during their virtual learning. However, a quarter (25\%) of students faced many obstacles. In general, teachers were rated as helpful to students while studying online. Only $5 \%$ of students proclaimed that teachers were not helpful, and $17 \%$ said slightly helpful. According to the results of the survey reported in Fig. 1, 78\% of the students managed their time well while learning online, and $93 \%$ revealed that the software (Blackboard Collaborate Ultra) was satisfactory and suitable for their online learning.

Fig. 2(a) and 2(b) show the students' response scores to the general and specific questions, respectively. In order to identify the students' appreciations reported in Fig. 2(a), score 3 was fixed as the threshold above which satisfaction was considered to be adequate. This figure indicates that all scores for Q12 to Q16 were below 3. It can be deduced from this figure that the students considered that virtual learning met their individual learning needs in comparison to face-to-face in-class learning (2.98/5). However, based on the fixed threshold, virtual learning was not more convenient than in-class learning. Moreover, it did not contribute to more effective communication compared to in-class learning. It also did not increase a sense of community with the instructor or fellow students. Additionally, according to students' scoring, online learning did not promote greater participation and interaction when compared to in-class learning.
Fig. 2(b) shows the variation of students' scores related to specific questions. It is worth noting that, except for Q19, based on the type of questions for this category, a score greater than the previously defined threshold (i.e., a score of 3 ), the appreciation of the students was considered unsatisfactory. Fig. 2(b) indicates that the virtual learning was, overall, working for students. In general, it can be seen that most students were satisfied with the virtual learning experience at PMU, averaging 3.34 out of 5. Furthermore, the students noted that the online technical workshop, training, and seminars could be conveniently accessed and incorporated into learning modules (3.41/5).

However, according to the students' responses, engineering field trips could not be conveniently substituted with virtual visits or tours (2.78/5). In fact, based on the comments of the students reported in Q22, as part of continuous learning, CE students enjoyed having virtual workshops or seminars that were regularly organized by the college or department, but they felt unsatisfied with virtual tours in comparison to actual engineering field trips. Moreover, online learning was more challenging in terms of conducting laboratory experiments or performing computer modeling simulation exercises (3.69/5).

During the campus closure, face-to-face instruction for the laboratory sessions was substituted with prerecorded laboratory work prepared by a lab instructor and technician, and the experimental outcomes and data were displayed to students for their further analysis and reporting. Limited live experiments, such as in the geotechnical lab, material lab, and engineering surveying lab, were broadcast to students using high-resolution cameras to allow students to experience engineering field work measurements. It was also more challenging to understand and perform engineering design exercises (3.53/5), and students were not satisfied with their learning about performing engineering design exercises as facilitated through Blackboard Collaborate Ultra.

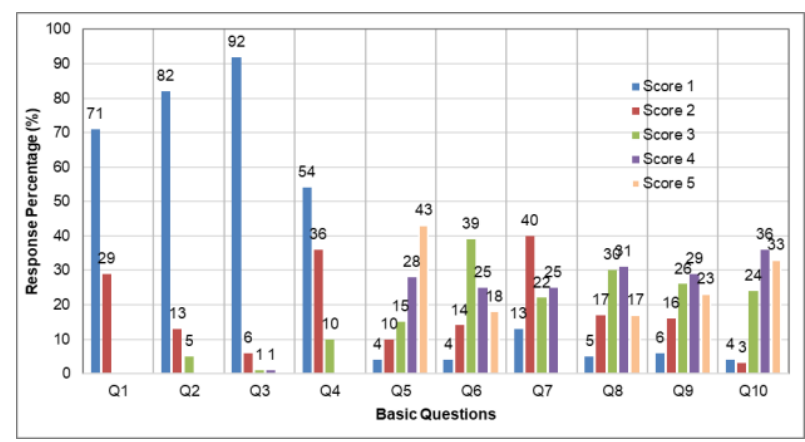

Fig. 1. Histogram of student response percentages on basic questions.

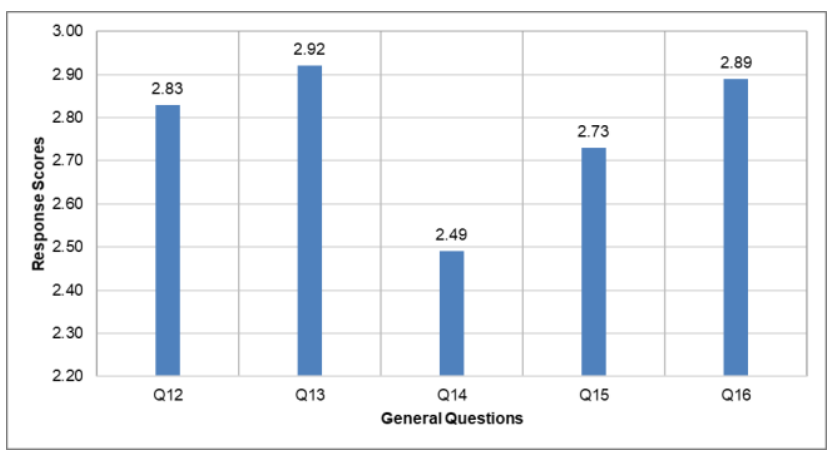

Fig. 2(a). Histogram of students' response scores for general questions. 


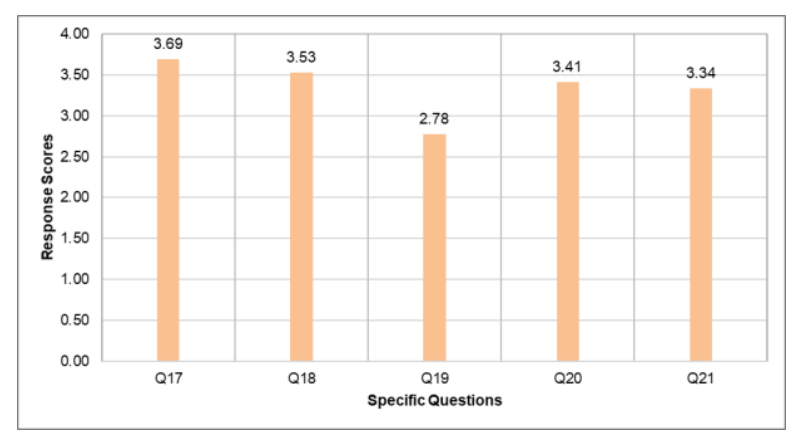

Fig. 2(b). Histogram of students' response scores for specific questions.

The comments from students about the greatest overall benefits of virtual learning-sorted out from the most frequently written-indicated they were 1) convenience in replaying recorded lectures, 2) reducing commute time from home to campus, and 3) increased class attendance and participation. The greatest drawbacks noted by students included 1) poor internet connection, 2) difficulties communicating with instructor and peers outside lecture times, and 3) online assessments. Suggestions provided by students to improve virtual learning included 1) using a hybrid approach that combines online and face-to-face instruction, 2) having the option to choose between online and face-to-face instruction, 3) improving virtual communication performance from instructors, and 4) monitoring online assessments. For all students, comments about improving the virtual learning environment centered on courses that require laboratory experiments for their learning outcomes, including running computer software for engineering design. The students suggested that limited access to engineering laboratories be given to them to overcome the lab issues. Working face-to-face with an instructor in the lab during the pandemic was not permitted because access to the physical campus was strictly forbidden for students, with only limited permits given to university staff. There are no substitutes for laboratory-based learning for engineering students. Assessing and measuring student skills by conducting laboratory experiments are among the important learning outcomes mandated by ABET. Once the restrictions were relaxed, the students' suggestions concerning laboratory experiments and computer modeling simulations were promptly taken into consideration, and all laboratory work and computer software work for engineering design were conducted face-to-face in a classroom on campus.

Moreover, to overcome the issue of poor internet connections, it will be recommended that students use a personal computer or laptop and not a cell phone to minimize interruptions when someone is phoning. Internet disconnection issues could lead to diminished focus on the lecture, and this can be minimized by replaying recorded lectures. Options to have face-to-face learning should be available in the future should some students have issues with accessing a good internet connection with a reliable personal computer or laptop. Communication with instructors during normal learning is facilitated by office hours. During virtual learning, students can still maximize communication via Blackboard Collaborate Ultra, provided that a specific link is given to students for online discussion. Other free and commercially available communication platforms (Zoom,
WhatsApp, etc.) can be used to create collaboration among student peers. Finally, the issue of reliably conducting virtual assessments can be overcome by requiring students to install additional software that can monitor and verify student activity during online quizzes or exams.

In the following subsections, the questions of categories II and III are examined against each question of category I. For this purpose, the questions from category I (i.e., basic questions) were divided into three different parts, as follows:

Part 1: Questions that examine the effect of equipment used (tools and devices) on students' online learning experiences (Q1 to Q3).

Part 2: Questions considering the effect of students' home environment on their online learning (Q4 to Q7).

Part 3: Questions dealing with the effects of the methods and technologies used on students' online learning (Q8 to Q10).

\section{A. Effect of Tools and Devices on Students' Online Learning Experience}

Conducting virtual sessions or distance learning work for different levels of students is very challenging [25], [26]. The survey results from the CE department at PMU also showed similar views on virtual methods. The results of the students' response scores for Q12 to Q21 in terms of the basic questions Q1 to Q3 (as shown in the results of Part 1) are given in Table I. The effects of high-speed internet, available devices, and assessment opportunities for virtual classes or distance (online) learning were evaluated from the survey results (derived from the basic questions Q1 to Q3). The survey results showed that $71 \%$ of students had high-speed internet, and $82 \%$ of students could access a device for online learning. About $92 \%$ of the students have personal laptops available for virtual learning, indicating the availability of technical supports in the students' community at PMU. The survey results also showed that a significant number of students did not have high-speed internet services, although they had devices and limited opportunities to access and participate in the virtual lessons (Table I).

In this study, the CE department investigation compared virtual learning with in-class learning in terms of convenience, learning needs, participation, and interaction. Most of the students expressed neutral or negative views, despite the presence of high-speed internet, available devices, and access opportunities (Fig. 3, 4, 5). The reasons for these responses are that students can have all the best devices and tools in place, but without equitable access in the home study environment for all students (during different situations) and adequate preparation and training for educators (for diversified courses), it is tough to replicate a traditional, in-person learning experience. For example, virtual learning is more challenging when it comes to conducting laboratory experiments or performing computer modeling simulation exercises. Moreover, online technical workshops, design-based training, and seminars are also difficult to conduct and cannot be conveniently accessed for diversified technical topics (e.g., engineering design exercises); thus, incorporation into learning modules is more challenging with tasks in different disciplines. The present survey results (shown in Table I and Figs. 3-5) also confirm similar views. 


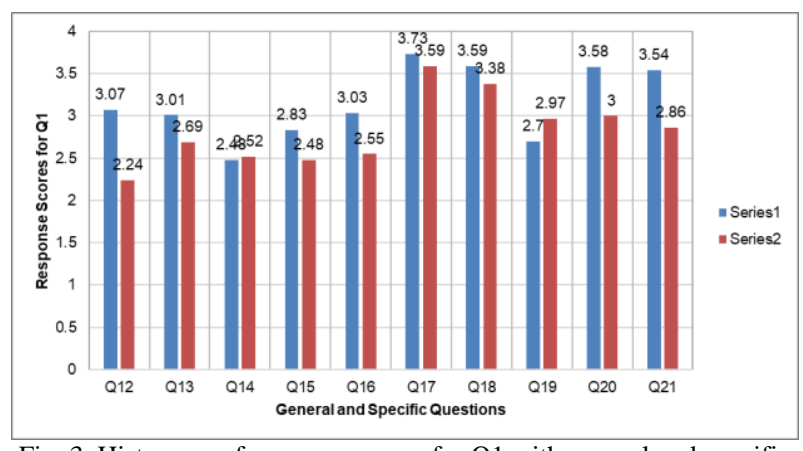

Fig. 3. Histogram of response scores for Q1 with general and specific questions.

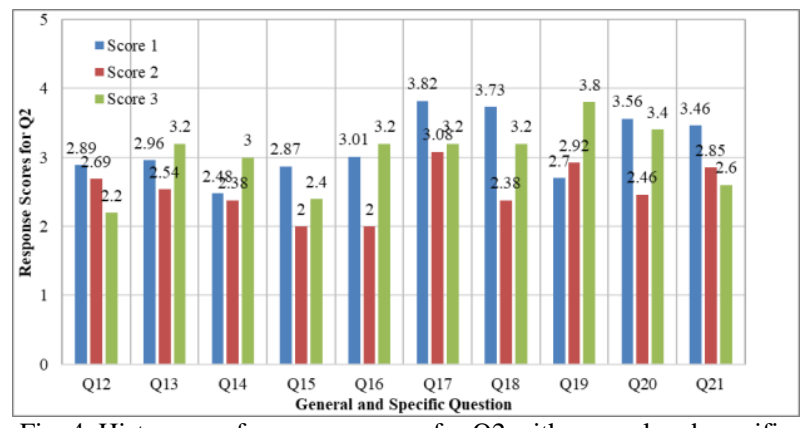

Fig. 4. Histogram of response scores for Q2 with general and specific questions.

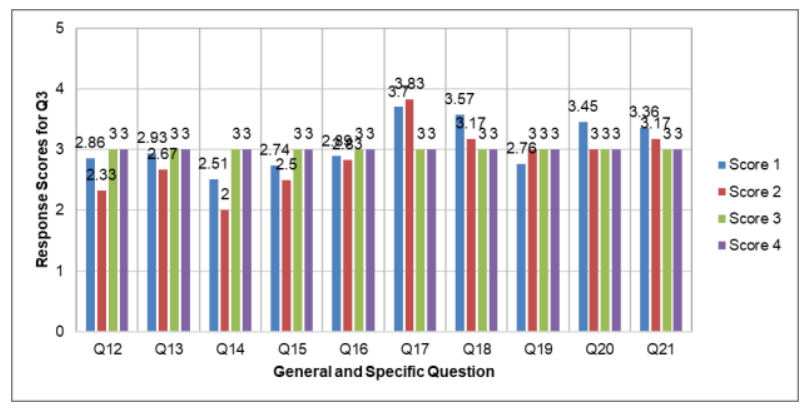

Fig. 5. Histogram of response scores for Q3 with general and specific questions.

In spite of having high-speed internet and access to a facility and device for virtual learning, students did not fully agree with the virtual learning processes (as shown in Table I). The results showed a poor score (e.g., 2/5) in the case of the effectiveness of the virtual learning environment for aspects of communication (Fig. 3). It is clear from the survey that despite adequate technical support and devices, the presence of virtual learning does not meet individual learning needs as well as in-class learning, and virtual learning is more challenging when it comes to understanding and performing engineering design exercises and laboratory experiments.

The student perception evaluated with the current survey could be changed significantly by adopting a few modifications, such as updating the existing curriculum or designing a brand new virtual-based syllabus that could be better matched with existing online tools. In addition to technical support, communicating and messaging effectively, facilitating discussions, assessing learning, enhancing delivery of lessons, and more clear video streaming can also overcome the common needs of students with virtual learning. Easy and user-friendly software for virtual classes can also keep students interested and active [27]. Furthermore, internet interruptions should be minimized in the region while conducting virtual classes.
The COVID-19 pandemic placed enormous forces on all academic institutions to close classrooms all over the world and forced millions of students and educators to change their face-to-face academic practices. Thus, it is high time for any academic institution to develop efficient and reliable virtual learning methods for every student so that they can have equal opportunities to participate in the lessons during the restrictions of a pandemic environment. Per requirements, the software tools used for online classes need to be updated with more options, features, and easier operating systems for both students and educators. More recording or other features should be incorporated in the virtual software in order to recover any unexpected interruptions while delivering or receiving the lectures. The virtual tools should also be suitable for portable devices so that students can easily open the session in any environment. These tools should be readily available and able to be operated with low-speed internet services, as well as be suitable for both portable and desktop devices. These digital issues can be resolved with thorough investigations as well as innovating digital applications in the academic environment. The school should use green and high-level technology, investing more funds to resolve the issues with online tools. It has been confirmed that student engagement in learning can be increased by adopting communication facilities, inquiring more about digital systems, choosing appropriate technologies, improving communication, using more technology (ICT), and educating both students and educators about digital issues, cloud adoption, and computing in general.

\section{B. Effect of Students' Home Environment on Online Learning Experience}

The results of the students' response scores for Q12 to Q21 in relation to the basic questions Q4 to Q7 (i.e., the results of Part 2) are summarized in Table II. As expected, the students who were learning online in a peaceful environment gave favorable answers to questions about that way of learning (Fig. 6). An adequate agreement was noted for all questions Q12 to Q21, except for Q14. The students agreed that virtual learning is generally working for them and is convenient relative to in-class learning. However, virtual learning did not contribute to more effective communication compared to in-class learning $(2.76 / 5)$. In the case of students working in disturbing or occasionally disturbing environments, there was much less agreement. In fact, except for questions Q17 and Q18, those students stated that virtual learning was generally not working properly for them. Most of the students, regardless of working environment, vigorously agreed that virtual learning is more challenging when it comes to conducting laboratory experiments or performing computer modeling simulation exercises (4.08/5). Also, they perceived and recognized that online learning is more challenging when it comes to understanding and performing engineering design exercises (4.06/5).

Fig. 7 shows students' response scores to Q5 presented against general and specific questions. It is clear from this figure that those students whose families were strongly or very helpful generally declared that virtual learning was more convenient and met their individual learning needs as compared to in-class learning. Nonetheless, once again, they 
indicated that virtual learning was more challenging for performing laboratory work, computer modeling simulations, and engineering design exercises. Furthermore, they proclaimed that online learning did not contribute to more effective communication compared to in-class learning, and it did not increase the sense of community with the instructor and fellow students. It is worth noting that students living with families who were only moderately helpful indicated that engineering field trips could be conveniently substituted with virtual visits and tours.

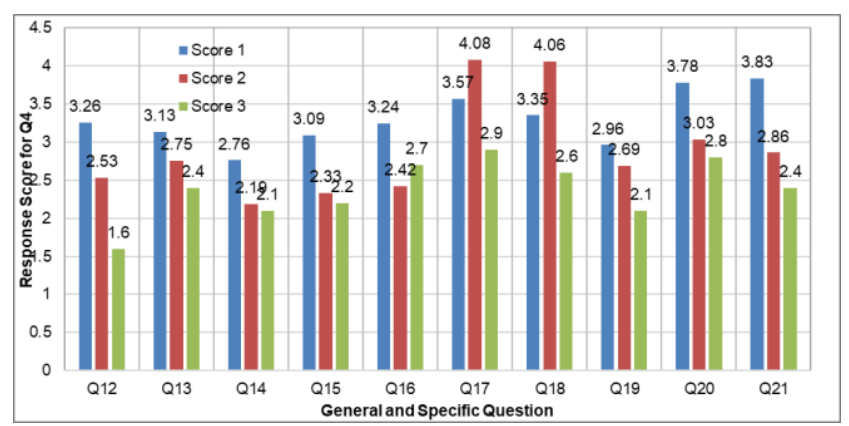

Fig. 6. Histogram of response scores for Q4 with general and specific questions.

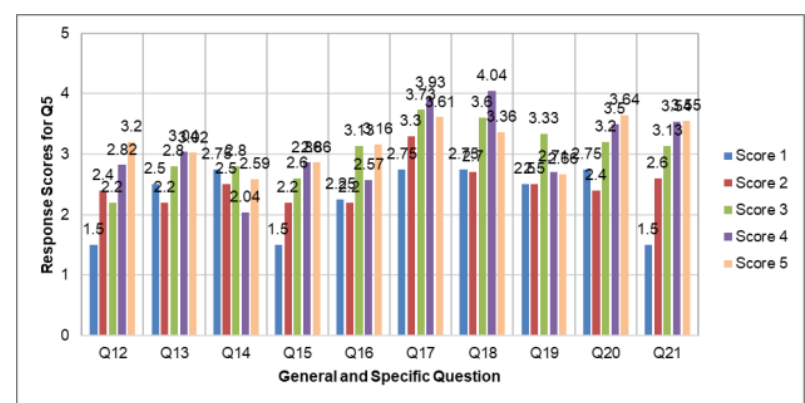

Fig. 7. Histogram of students' response scores for Q5 with general and specific questions.

The variation of students' response scores for Q6 against general and specific questions is presented in Fig. 8. It can be deduced from this figure that students whose coworkers were strongly or very helpful were more appreciative and found online learning to be convenient. They firmly agreed that virtual learning was working and more convenient for them as compared to in-class learning. However, similar to students' responses for Q4 and Q5, they perceived that virtual learning did not contribute to more effective communication as compared to conventional learning.

TABLE I: RESULTS OF STUDENTS’ RESPONSE SCORES FOR Q1 TO Q3 IN COMPARISON TO Q12 TO Q21

\begin{tabular}{|c|c|c|c|c|c|c|c|c|c|c|c|c|}
\hline \multirow{2}{*}{ Questions } & & & \multicolumn{10}{|c|}{ Results of the Survey } \\
\hline & Ans. & $\%$ & Q. 12 & Q. 13 & Q. 14 & Q. 15 & Q.16 & Q. 17 & Q. 18 & Q. 19 & Q. 20 & Q. 21 \\
\hline \multirow{6}{*}{ 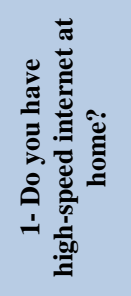 } & 1 & \multirow{3}{*}{71} & 3.07 & 3.01 & 2.48 & 2.83 & 3.03 & 3.73 & 3.59 & 2.7 & 3.58 & 3.54 \\
\hline & SD & & 1.26 & 1.13 & 1.13 & 1.11 & 1.28 & 1.33 & 1.39 & 1.46 & 1.09 & 1.08 \\
\hline & mode & & 3 & 3 & 2 & 3 & 3 & 5 & 5 & 1 & 3 & 3 \\
\hline & 2 & \multirow{3}{*}{29} & 2.24 & 2.69 & 2.52 & 2.48 & 2.55 & 3.59 & 3.38 & 2.97 & 3 & 2.86 \\
\hline & SD & & 1.02 & 0.97 & 1.21 & 0.87 & 1.09 & 1.02 & 1.35 & 1.09 & 1.16 & 1.06 \\
\hline & Mode & & 3 & 3 & 2 & 3 & 3 & 3 & 3 & 3 & 3 & 3 \\
\hline \multirow{9}{*}{ 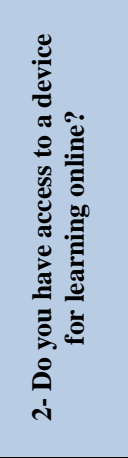 } & 1 & \multirow{3}{*}{82} & 2.89 & 2.96 & 2.48 & 2.87 & 3.01 & 3.82 & 3.73 & 2.7 & 3.56 & 3.46 \\
\hline & SD & & 1.25 & 1.08 & 1.15 & 1.03 & 1.24 & 1.25 & 1.32 & 1.41 & 1.11 & 1.08 \\
\hline & Mode & & 3 & 3 & 2 & 3 & 3 & 5 & 5 & 1 & 3 & 3 \\
\hline & 2 & \multirow{3}{*}{13} & 2.69 & 2.54 & 2.38 & 2 & 2 & 3.08 & 2.38 & 2.92 & 2.46 & 2.85 \\
\hline & SD & & 1.03 & 1.05 & 1.19 & 0.91 & 0.91 & 1.12 & 1.26 & 0.95 & 0.97 & 1.21 \\
\hline & Mode & & 3 & 3 & 3 & 3 & 3 & 3 & 3 & 3 & 2 & 3 \\
\hline & 3 & \multirow{3}{*}{5} & 2.2 & 3.2 & 3 & 2.4 & 3.2 & 3.2 & 3.2 & 3.8 & 3.4 & 2.6 \\
\hline & SD & & 1.79 & 1.3 & 1.22 & 1.14 & 1.1 & 1.1 & 1.3 & 1.1 & 0.89 & 0.89 \\
\hline & Mode & & 1 & 2 & 2 & 2 & 3 & 3 & 2 & 3 & 3 & 3 \\
\hline \multirow{12}{*}{ 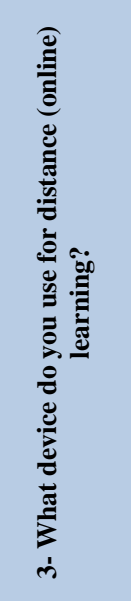 } & 1 & \multirow{3}{*}{92} & 2.86 & 2.93 & 2.51 & 2.74 & 2.89 & 3.7 & 3.57 & 2.76 & 3.45 & 3.36 \\
\hline & SD & & 1.25 & 1.13 & 1.19 & 1.09 & 1.29 & 1.26 & 1.39 & 1.42 & 1.15 & 1.14 \\
\hline & Mode & & 3 & 3 & 2 & 3 & 3 & 5 & 5 & 3 & 3 & 3 \\
\hline & 2 & \multirow{3}{*}{6} & 2.33 & 2.67 & 2 & 2.5 & 2.83 & 3.83 & 3.17 & 3 & 3 & 3.17 \\
\hline & SD & & 1.51 & 0.52 & 0 & 0.55 & 0.41 & 1.33 & 1.33 & 0 & 1.1 & 0.75 \\
\hline & Mode & & 1 & 3 & 2 & 3 & 3 & 5 & 2 & 3 & 3 & 3 \\
\hline & 3 & \multirow{3}{*}{1} & 3 & 3 & 3 & 3 & 3 & 3 & 3 & 3 & 3 & 3 \\
\hline & SD & & - & - & - & - & - & - & - & - & - & - \\
\hline & Mode & & - & - & - & - & - & - & - & - & - & - \\
\hline & 4 & \multirow{3}{*}{1} & 3 & 3 & 3 & 3 & 3 & 3 & 3 & 3 & 3 & 3 \\
\hline & SD & & - & - & - & - & - & - & - & - & - & - \\
\hline & Mode & & - & - & - & - & - & - & - & - & - & - \\
\hline
\end{tabular}


TABLE II: RESULTS OF STUDENTS' RESPONSE SCORES FOR Q4 TO Q7 IN COMPARISON TO Q12 TO Q21

\begin{tabular}{|c|c|c|c|c|c|c|c|c|c|c|c|c|}
\hline \multirow[b]{2}{*}{ Questions } & \multirow[b]{2}{*}{ Ans. } & \multirow{2}{*}{$\%$} & \multicolumn{10}{|c|}{ Results of the Survey } \\
\hline & & & Q. 12 & Q.13 & Q.14 & Q.15 & Q.16 & Q.17 & Q.18 & Q.19 & Q.20 & $\overline{Q .21}$ \\
\hline \multirow{9}{*}{ 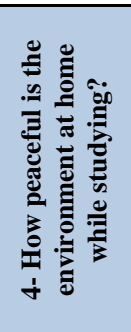 } & 1 & \multirow{3}{*}{54} & 3.26 & 3.13 & 2.76 & 3.09 & 3.24 & 3.57 & 3.35 & 2.96 & 3.78 & 3.83 \\
\hline & SD & & 1.07 & 1.01 & 1.06 & 0.96 & 1.22 & 1.28 & 1.3 & 1.22 & 0.98 & 0.98 \\
\hline & Mode & & 3 & 3 & 2 & 3 & 3 & 5 & 3 & 3 & 3 & 3 \\
\hline & 2 & \multirow{3}{*}{36} & 2.53 & 2.75 & 2.19 & 2.33 & 2.42 & 4.08 & 4.06 & 2.69 & 3.03 & 2.86 \\
\hline & SD & & 1.25 & 1.05 & 1.14 & 1.01 & 1.05 & 1.05 & 1.31 & 1.49 & 1.16 & 0.83 \\
\hline & Mode & & 3 & 3 & 1 & 3 & 3 & 5 & 5 & 1 & 2 & 3 \\
\hline & 3 & \multirow{3}{*}{10} & 1.6 & 2.4 & 2.1 & 2.2 & 2.7 & 2.9 & 2.6 & 2.1 & 2.8 & 2.4 \\
\hline & SD & & 0.97 & 1.35 & 1.29 & 0.92 & 1.34 & 1.2 & 1.26 & 1.37 & 1.23 & 1.35 \\
\hline & Mode & & 1 & 1 & 1 & 3 & 3 & 3 & 2 & 1 & 3 & 3 \\
\hline \multirow{15}{*}{ 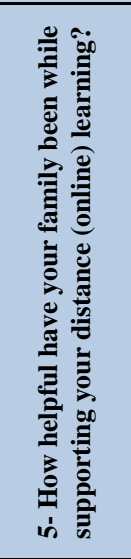 } & 1 & \multirow{3}{*}{4} & 1.5 & 2.5 & 2.75 & 1.5 & 2.25 & 2.75 & 2.75 & 2.5 & 2.75 & 1.5 \\
\hline & $\mathrm{SD}$ & & 1 & 1.91 & 2.06 & 1 & 1.89 & 1.71 & 1.71 & 1.91 & 1.71 & 1 \\
\hline & Mode & & 1 & 1 & 1 & 1 & 1 & - & - & 1 & - & 1 \\
\hline & 2 & \multirow{3}{*}{10} & 2.4 & 2.2 & 2.5 & 2.2 & 2.2 & 3.3 & 2.7 & 2.5 & 2.4 & 2.6 \\
\hline & SD & & 0.97 & 0.92 & 1.18 & 0.92 & 0.92 & 1.16 & 1.49 & 0.71 & 0.7 & 0.7 \\
\hline & Mode & & 3 & 3 & 3 & 3 & 3 & 3 & 3 & 3 & 3 & 3 \\
\hline & 3 & \multirow{3}{*}{15} & 2.2 & 2.8 & 2.8 & 2.6 & 3.13 & 3.73 & 3.6 & 3.33 & 3.2 & 3.13 \\
\hline & SD & & 1.01 & 1.01 & 1.15 & 1.06 & 0.83 & 1.22 & 1.35 & 1.63 & 0.77 & 1.13 \\
\hline & Mode & & 3 & 3 & 3 & 3 & 3 & 3 & 5 & 5 & 3 & 3 \\
\hline & 4 & \multirow{3}{*}{28} & 2.82 & 3.04 & 2.04 & 2.86 & 2.57 & 3.93 & 4.04 & 2.71 & 3.5 & 3.54 \\
\hline & SD & & 1.36 & 0.88 & 1 & 1.04 & 1.29 & 1.09 & 0.88 & 1.05 & 1.07 & 1.14 \\
\hline & Mode & & 3 & 3 & 2 & 3 & 3 & 5 & 5 & 3 & 4 & 3 \\
\hline & 5 & \multirow{3}{*}{43} & 3.2 & 3.02 & 2.59 & 2.86 & 3.16 & 3.61 & 3.36 & 2.66 & 3.64 & 3.55 \\
\hline & SD & & 1.14 & 1.15 & 1.11 & 1.01 & 1.23 & 1.32 & 1.5 & 1.5 & 1.18 & 0.95 \\
\hline & Mode & & 3 & 3 & 2 & 3 & 3 & 5 & 5 & 1 & 5 & 3 \\
\hline \multirow{15}{*}{ 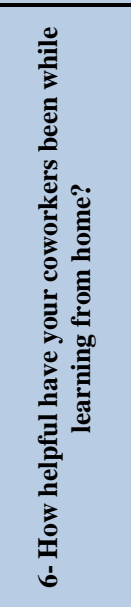 } & 1 & \multirow{3}{*}{4} & 2 & 2 & 2 & 1.5 & 2 & 3.5 & 3.25 & 3 & 3.25 & 1.5 \\
\hline & SD & & 2 & 2 & 2 & 1 & 2 & 1.91 & 2.06 & 2.31 & 2.06 & 1 \\
\hline & Mode & & 1 & 1 & 1 & 1 & 1 & 5 & 5 & 1 & 5 & 1 \\
\hline & 2 & & 3.21 & 3.07 & 3 & 2.93 & 3.21 & 3.64 & 3.71 & 2.36 & 3.07 & 3.29 \\
\hline & SD & 14 & 0.58 & 0.62 & 1.11 & 1.21 & 0.97 & 0.84 & 0.91 & 0.93 & 0.83 & 0.73 \\
\hline & Mode & & 3 & 3 & 2 & 3 & 3 & 4 & 4 & 3 & 3 & 3 \\
\hline & 3 & & 2.41 & 2.59 & 2.21 & 2.41 & 2.44 & 3.67 & 3.41 & 2.59 & 3.1 & 3.23 \\
\hline & SD & 39 & 1.39 & 1.14 & 1.13 & 1.04 & 1.23 & 1.18 & 1.39 & 1.21 & 1.12 & 1.22 \\
\hline & Mode & & 1 & 3 & 2 & 3 & 3 & 3 & 5 & 3 & 3 & 3 \\
\hline & 4 & & 2.88 & 3.16 & 2.68 & 3.2 & 3.4 & 4.32 & 4.24 & 2.64 & 4 & 3.4 \\
\hline & SD & 25 & 1.13 & 0.9 & 1.11 & 0.82 & 1.04 & 0.99 & 1.2 & 1.52 & 0.91 & 0.96 \\
\hline & Mode & & 3 & 3 & 2 & 3 & 3 & 5 & 5 & 1 & 5 & 3 \\
\hline & 5 & & 3.56 & 3.39 & 2.56 & 2.89 & 3.11 & 2.94 & 2.72 & 3.67 & 3.56 & 3.94 \\
\hline & SD & 18 & 0.86 & 1.04 & 0.98 & 0.9 & 1.18 & 1.47 & 1.32 & 1.24 & 1.2 & 0.87 \\
\hline & Mode & & 3 & 3 & 3 & 3 & 2 & 4 & 3 & 5 & 5 & 3 \\
\hline & 1 & & 3.23 & 3.54 & 3.08 & 3.38 & 4.15 & 3.31 & 3.23 & 3.08 & 4.38 & 4.23 \\
\hline 送 & SD & 13 & 1.42 & 1.13 & 1.26 & 0.96 & 0.9 & 1.8 & 1.69 & 1.55 & 0.87 & 0.83 \\
\hline 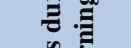 & Mode & & 4 & 4 & 2 & 3 & 5 & 5 & 1 & 3 & 5 & 5 \\
\hline 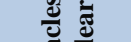 & 2 & & 3.4 & 3.13 & 2.6 & 2.9 & 3 & 3.83 & 3.7 & 2.73 & 3.63 & 3.75 \\
\hline$\frac{\pi}{8}$ & SD & 40 & 1.03 & 0.97 & 1.01 & 1.1 & 1.13 & 1.06 & 1.11 & 1.4 & 1.1 & 0.84 \\
\hline$\geq$ & Mode & & 3 & 3 & 3 & 3 & 3 & 5 & 3 & 3 & 3 & 3 \\
\hline ह & 3 & & 2.68 & 2.77 & 2.32 & 2.55 & 2.5 & 3.41 & 3 & 2.59 & 2.86 & 3.23 \\
\hline 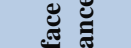 & SD & 22 & 0.89 & 1.07 & 1.21 & 0.74 & 1.01 & 0.96 & 1.27 & 0.96 & 0.89 & 1.07 \\
\hline$\tilde{z}=$ & Mode & & 3 & 3 & 2 & 3 & 3 & 3 & 3 & 2 & 3 & 3 \\
\hline$=$ & 4 & & 1.84 & 2.4 & 2.16 & 2.28 & 2.4 & 3.92 & 3.88 & 2.88 & 3.04 & 2.32 \\
\hline & SD & 25 & 1.14 & 1.08 & 1.18 & 1.06 & 1.29 & 1.38 & 1.56 & 1.54 & 1.14 & 0.9 \\
\hline & Mode & & 1 & 3 & 1 & 3 & 1 & 5 & 5 & 3 & 3 & 3 \\
\hline
\end{tabular}

As anticipated, students who did not face any obstacles (or had only slight obstacles) during their virtual learning proclaimed a convenient or suitable appreciation concerning their virtual learning (Fig. 9). They firmly agreed that virtual learning was working properly for them. Furthermore, they strongly admit that virtual learning promotes greater participation and interaction compared to in-class learning. Also, these students noted that online technical workshops, trainings, and seminars could be conveniently accessed and incorporated into learning modules.
Based on the results and scores obtained for questions Q4 to Q7 about the effect of students' home environments on their virtual learning experience, it can be summarized that the ideal students' environment for performing virtual learning is to work in a peaceful environment, have supportive and helpful families and coworkers, and face minimal obstacles. However, all students, regardless of their working environment, agreed that online learning does not contribute to more effective communication compared to in-class learning. Again, they also agreed that online learning 
is more challenging for conducting experiments or performing computer modeling simulation and engineering design exercises. The different values calculated for the standard deviation, grouped in Table II, are less than 2, showing that the data are clustered closely around the mean (which is more reliable). Furthermore, the coefficient of variation, defined as the ratio of the standard deviation to the mean, was less than 1 , indicating a relatively low variation in the results.

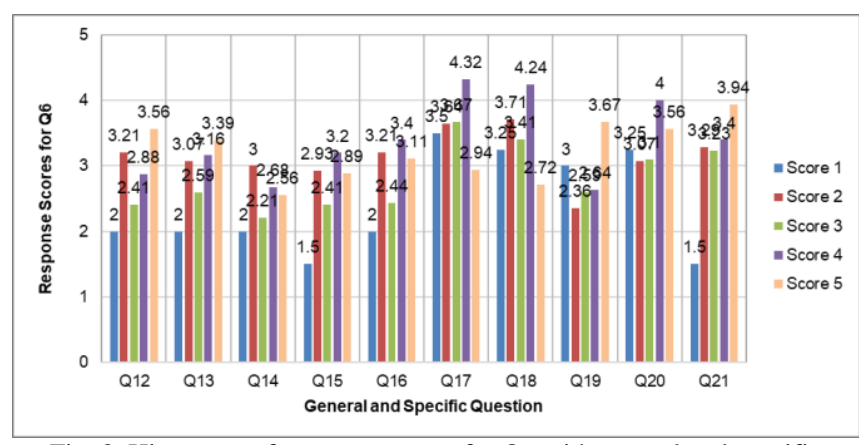

Fig. 8. Histogram of response scores for Q6 with general and specific questions.

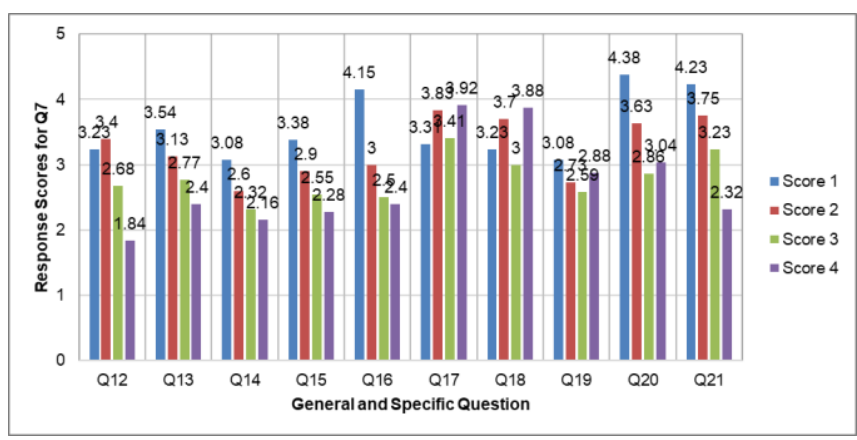

Fig. 9. Histogram of response scores for Q7 with general and specific questions.

\section{Effect of Methods and Technologies on Students' Online Learning Experience}

The results of the students' response scores for Q12 to Q21 against the basic questions Q8 to Q10 (i.e., the results of Part 3) are summarized in Table III. As anticipated, students who thought that teachers were moderately helpful, very helpful, or extremely helpful while studying online had better feelings about their virtual learning experiences, as shown in their responses to the general and specific questions (Q12 to Q21). A similar trend was also seen among students who had better time management skills and who felt satisfied with the Blackboard Collaborate Ultra as their virtual learning platform. Question 14 is always an exception (see Fig. 2a), indicating how students feel negatively about effective communication when it comes to virtual learning. These findings are further supported by Fig. 1.

In general, the level and quality of help provided by teachers (Q8) reflect directly on students' virtual learning experiences (Fig. 10). This can be seen clearly in questions 12 to 16 (general questions), except question 14, as indicated above. Similar findings were seen for questions 19 to 21 ; students who evaluated their teachers as helpful (scores 3, 4, and 5) felt that field trips could be conveniently substituted with virtual visits and that technical workshops/training/seminars can be conveniently accessed and incorporated into learning modules. They said that, generally, the distance (online) learning program was working for them. Surprisingly, when it comes to conducting laboratory experimentation, performing computer modeling design exercises, or when understanding and performing design problems (Q17 and Q18), students who thought teachers were not at all helpful disagreed that virtual learning is more challenging in terms of laboratory work, computer simulation exercises, and design problems!

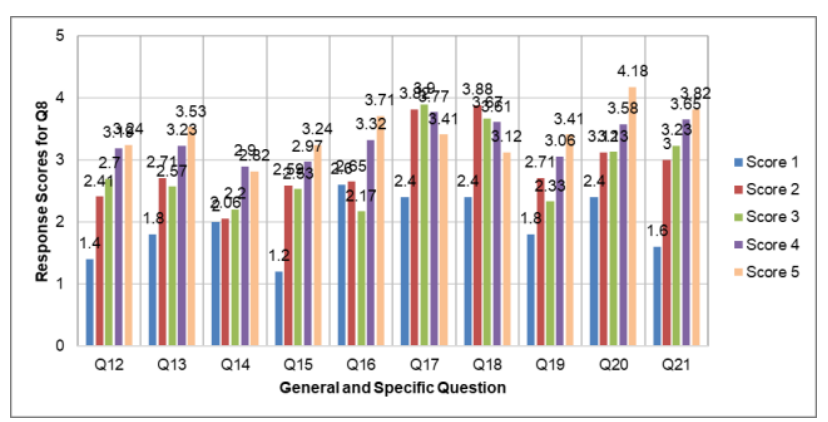

Fig. 10. Histogram of response scores for Q8 with general and specific questions.

Time management is a much-needed soft skill at all times, and it becomes more prominent when functioning within unusual circumstances, such as the COVID-19 pandemic (Q9). Fig. 11 displays how well students implemented time management while learning online against the general and specific questions (Q12 to Q21). Fig. 11 shows the importance of time management during virtual learning and shows that students with better time management skills had better virtual learning experiences. Once again, Q17 and Q18 presented inconsistent results, Q14 remained an exception, and Q21 revealed that the distance (online) learning program was generally working for students.

It is well known that any virtual program cannot be effectively evaluated without exploring the satisfaction level with the virtual platform being used (Q10). In this study, the Blackboard Collaborate Ultra was used, and students showed general satisfaction with this online platform for properly handling the job. It can be seen in Fig. 12 that students who thought the Blackboard Collaborate Ultra platform was satisfactory wound up with better virtual learning experiences, based on their responses and scores to the general and specific questions (Q12 to Q21). When evaluated against Q10, Q14 again showed that virtual learning is not helping students demonstrate and promote their communication skills as it should be.

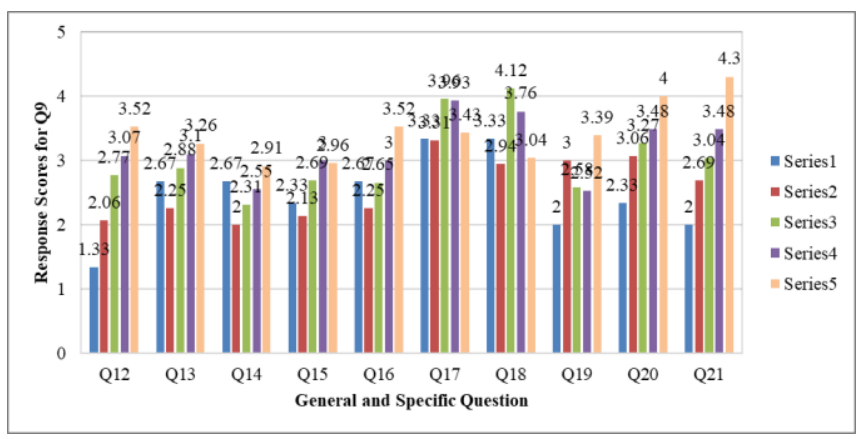

Fig. 11. Histogram of response scores for Q9 with general and specific questions. 
TABLE III: RESULTS OF STUDENTS' RESPONSE SCORES FOR Q8 TO Q10 IN COMPARISON TO Q12 TO Q21

\begin{tabular}{|c|c|c|c|c|c|c|c|c|c|c|c|c|}
\hline \multirow{2}{*}{ Questions } & \multirow{2}{*}{ Ans. } & \multirow{2}{*}{$\%$} & \multicolumn{10}{|c|}{ Results of the Survey } \\
\hline & & & Q.12 & Q.13 & Q.14 & Q.15 & Q.16 & Q.17 & Q.18 & Q.19 & Q. 20 & Q.21 \\
\hline \multirow{15}{*}{ 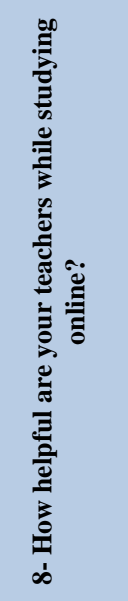 } & 1 & \multirow{3}{*}{5} & 1.4 & 1.8 & 2 & 1.2 & 2.6 & 2.4 & 2.4 & 1.8 & 2.4 & 1.6 \\
\hline & SD & & 0.89 & 1.3 & 1.73 & 0.45 & 1.82 & 1.95 & 1.95 & 1.79 & 1.67 & 0.89 \\
\hline & Mode & & 1 & 1 & 1 & 1 & 1 & 1 & 1 & 1 & 1 & 1 \\
\hline & 2 & \multirow{3}{*}{17} & 2.41 & 2.71 & 2.06 & 2.59 & 2.65 & 3.82 & 3.88 & 2.71 & 3.12 & 3 \\
\hline & SD & & 0.94 & 0.92 & 0.97 & 0.62 & 1.22 & 1.19 & 1.22 & 0.99 & 0.99 & 1 \\
\hline & Mode & & 3 & 3 & 1 & 3 & 3 & 5 & 5 & 3 & 3 & 3 \\
\hline & 3 & \multirow{3}{*}{30} & 2.7 & 2.57 & 2.2 & 2.53 & 2.17 & 3.9 & 3.67 & 2.33 & 3.13 & 3.23 \\
\hline & SD & & 1.32 & 1.07 & 1.21 & 1.07 & 0.99 & 0.92 & 1.4 & 1.12 & 1.04 & 1.1 \\
\hline & Mode & & 3 & 3 & 2 & 3 & 3 & 3 & 5 & 3 & 2 & 3 \\
\hline & 4 & \multirow{3}{*}{31} & 3.19 & 3.23 & 2.9 & 2.97 & 3.32 & 3.77 & 3.61 & 3.06 & 3.58 & 3.65 \\
\hline & SD & & 1.19 & 0.88 & 1.01 & 1.05 & 0.94 & 1.09 & 1.12 & 1.41 & 0.99 & 0.98 \\
\hline & Mode & & 3 & 3 & 3 & 3 & 3 & 3 & 3 & 3 & 3 & 3 \\
\hline & 5 & \multirow{3}{*}{17} & 3.24 & 3.53 & 2.82 & 3.24 & 3.71 & 3.41 & 3.12 & 3.41 & 4.18 & 3.82 \\
\hline & SD & & 1.2 & 1.12 & 1.01 & 1.03 & 1.26 & 1.66 & 1.62 & 1.54 & 1.13 & 0.95 \\
\hline & Mode & & 3 & 4 & 2 & 3 & 5 & 5 & 4 & 5 & 5 & 3 \\
\hline \multirow{15}{*}{ 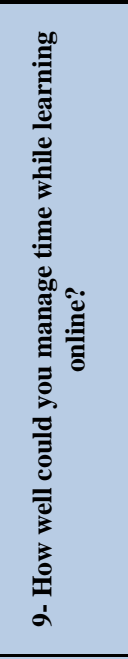 } & 1 & \multirow{3}{*}{6} & 1.33 & 2.67 & 2.67 & 2.33 & 2.67 & 3.33 & 3.33 & 2 & 2.33 & 2 \\
\hline & SD & & 0.82 & 1.51 & 1.51 & 1.51 & 1.51 & 1.97 & 1.97 & 1.67 & 1.51 & 1.1 \\
\hline & Mode & & 1 & 3 & 3 & 1 & 3 & 5 & 5 & 1 & 1 & 1 \\
\hline & 2 & \multirow{3}{*}{16} & 2.06 & 2.25 & 2 & 2.13 & 2.25 & 3.31 & 2.94 & 3 & 3.06 & 2.69 \\
\hline & SD & & 1.18 & 1 & 1.1 & 1.15 & 1.39 & 1.08 & 1.53 & 0.73 & 0.77 & 0.79 \\
\hline & Mode & & 1 & 2 & 1 & 1 & 1 & 3 & 3 & 3 & 3 & 3 \\
\hline & 3 & \multirow{3}{*}{26} & 2.77 & 2.88 & 2.31 & 2.69 & 2.65 & 3.96 & 4.12 & 2.58 & 3.27 & 3.04 \\
\hline & SD & & 1.27 & 1.03 & 1.19 & 1.01 & 1.09 & 1.04 & 1.03 & 1.65 & 1.12 & 1 \\
\hline & Mode & & 3 & 3 & 2 & 3 & 3 & 5 & 5 & 1 & 3 & 3 \\
\hline & 4 & \multirow{3}{*}{29} & 3.07 & 3.1 & 2.55 & 3 & 3 & 3.93 & 3.76 & 2.52 & 3.48 & 3.48 \\
\hline & SD & & 1.07 & 0.98 & 0.99 & 0.8 & 1.2 & 1.1 & $\begin{array}{l}1.18 \\
\end{array}$ & 1.15 & 1.24 & 0.91 \\
\hline & Mode & & 3 & 3 & 3 & 3 & 3 & 5 & 5 & 3 & 5 & 3 \\
\hline & 5 & \multirow{3}{*}{23} & 3.52 & 3.26 & 2.91 & 2.96 & 3.52 & 3.43 & 3.04 & 3.39 & 4 & 4.3 \\
\hline & SD & & 0.99 & 1.1 & 1.16 & 1.07 & 1.04 & 1.47 & 1.43 & 1.34 & 0.85 & 0.88 \\
\hline & Mode & & 3 & 3 & 2 & 3 & 3 & 5 & 3 & 3 & 3 & 5 \\
\hline \multirow{15}{*}{ 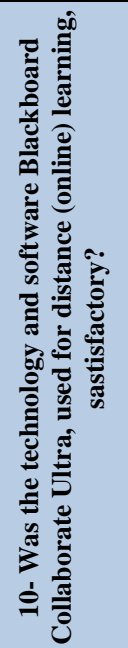 } & 1 & \multirow{3}{*}{4} & 1.5 & 2.5 & 2.5 & 1.5 & 2.5 & 2.5 & 2.5 & 2.5 & 2.5 & 1.5 \\
\hline & SD & & 1 & 1.91 & 1.91 & 1 & 1.91 & 1.91 & 1.91 & 1.91 & 1.91 & 1 \\
\hline & Mode & & 1 & 1 & 1 & 1 & 1 & 1 & 1 & 1 & 1 & 1 \\
\hline & 2 & \multirow{3}{*}{3} & 3 & 3 & 2.67 & 3 & 3 & 3.33 & 4 & 3 & 2.67 & 3.33 \\
\hline & SD & & 2 & 1 & 1.53 & 1 & 1.73 & 1.53 & 1 & 2 & 0.58 & 1.53 \\
\hline & Mode & & - & - & - & - & 2 & - & - & - & 3 & - \\
\hline & 3 & & 2.54 & 2.29 & 2.25 & 2.42 & 2.67 & 3.63 & 2.96 & 2.88 & 3.04 & 2.88 \\
\hline & SD & 24 & 1.35 & 1.08 & 1.03 & 0.97 & 1.2 & 1.13 & 1.43 & 1.19 & 1.04 & 1.03 \\
\hline & Mode & & 3 & 3 & 3 & 3 & 3 & 3 & 3 & 3 & 2 & 3 \\
\hline & 4 & & 3.11 & 3.14 & 2.58 & 2.81 & 2.72 & 3.69 & 3.69 & 2.44 & 3.61 & 3.58 \\
\hline & SD & 36 & 1.21 & 0.96 & 1.27 & 1.06 & 1.16 & 0.98 & 1.04 & 1.25 & 1.05 & 1.05 \\
\hline & Mode & & 3 & 3 & 2 & 3 & 3 & 3 & 3 & 2 & 3 & 3 \\
\hline & 5 & & 2.88 & 3.18 & 2.55 & 3 & 3.27 & 3.91 & 3.85 & 3.09 & 3.64 & 3.64 \\
\hline & SD & 33 & 1.08 & 0.98 & 1 & 1 & 1.21 & 1.44 & 1.5 & 1.47 & 1.14 & 0.93 \\
\hline & Mode & & 3 & 3 & 2 & 3 & 3 & 5 & 5 & 3 & 3 & 3 \\
\hline
\end{tabular}

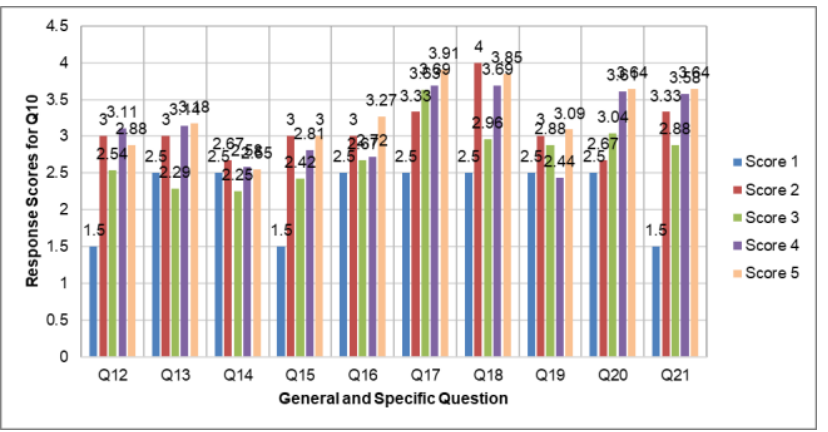

Fig. 12. Histogram of response scores for Q10 with general and specific questions.
Based on the results discussed above, more focus should be placed on promoting communication skills as an integral part of an online learning program. Activities such as term projects, end-of-semester presentations, smaller group assignments during online lectures, and so on could help in this regard. Additionally, laboratory experimentation, computer modeling exercises, and design problems should be addressed in a more efficient way [28]-[30]. This could be attained by adopting commercially available virtual labs (some are free and open-source software), simulation-based engineering tools for design and computer modeling 
purposes, desktop apps, and other educational engineering software. Finally, it is worth mentioning at this point that the coefficient of variation, which is a measure of the dispersion of a data set, for questions 8 to 10 was less than 1 , indicating relatively low variation in the results. This is also emphasized by the calculated values of standard deviations, which is another measure of scatterings, that are shown in Table III.

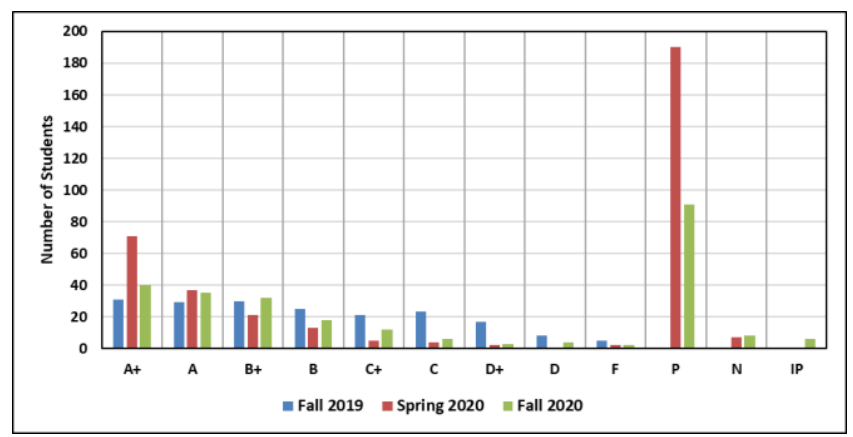

Fig. 13. Grade distributions for key civil engineering courses.

\section{Grade Distribution for Key Civil Engineering Courses}

Grade distribution was examined to indirectly see how convenient students found dealing with the virtual learning assessment. Near the end of the spring term 2020, a new (additional) grading system was introduced at PMU to relieve pressure from students experiencing sudden changes in the learning modality. As practiced at most universities around the world, students were given two options for their grade assessments, either pass/fail or a traditional letter grade. The major difference between these two was in the optional final exam participation, depending on the grade performance prior to the final exam. Students who met $65 \%$ of the total grade before the final exam would have the option to either be assigned a passing grade without the need to take the final exam, or they could take the final exam and receive a traditional letter grade that included the final exam result. Fig. 13 shows the grade distribution since the last normal time (Fall 2019) for courses taken by CE students at the sophomore, junior, and senior levels. It can be seen that, in general, the majority of students were comfortable taking the pass/fail option during the spring 2020 and fall 2020 terms, but the number decreased from 54\% in the spring of 2020 to $39 \%$ in the fall of 2020 . This could be attributed to student confidence and familiarity with virtual learning. Students taking the traditional letter grade option can be said to be a combination of confident students trying to maintain a good grade-point average (GPA) and students who did not want to change their already excellent GPA.

\section{CONCLUSION}

Based on the survey conducted at PMU, it can be concluded that the majority of the student population, including engineering students, were satisfied with the virtual learning practice conducted using the existing teaching platform. This could be attributed to a certain degree of familiarity of the student experience with the online teaching platform that had been used during normal in-class instruction. It should be noted, however, that the observations obtained in this study were based on two semesters of conducting the virtual learning modality. However, for engineering and other science programs, challenges still lie ahead in anticipating learning needs for laboratory-based teaching. As other studies observed, it would not be wise for laboratory-based courses to rely heavily on the virtual modality because students must have first-hand experience learning experimentation. Limited access to laboratories due to precautionary measures is suggested in the near future should the pandemic go beyond the fall term, so the possibility of using hybrid learning methods needs to be implemented for laboratory-based teaching, where students can follow experimental procedures via virtual teaching and execute the experiments in the actual lab environment via a team effort.

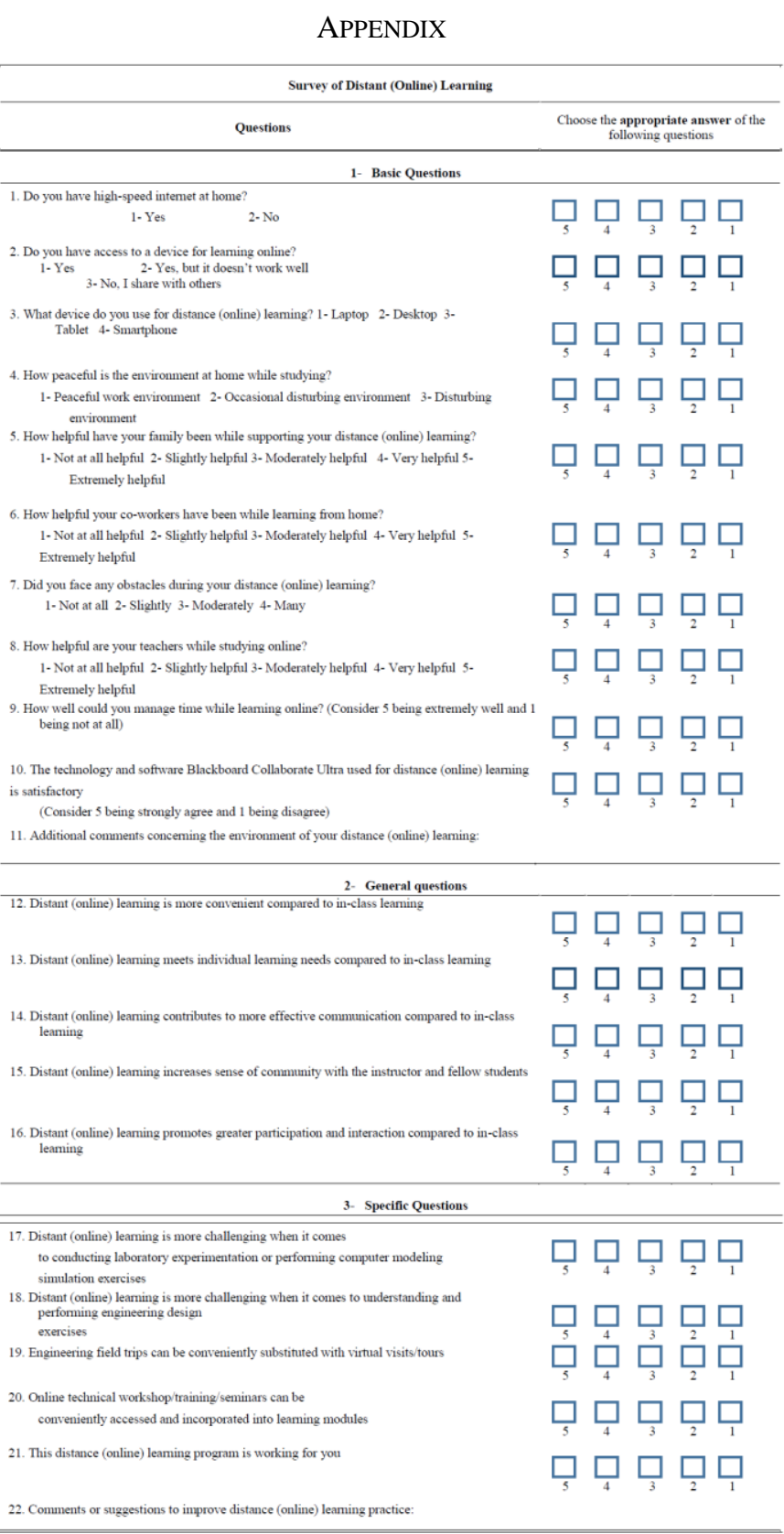

\section{CONFLICTS OF INTEREST}

The authors declare no conflicts of interest. 


\section{Author Contributions}

Dr. Tahar Ayadat contributed to the survey, analysis, and write-up. Dr. Mohammad Ali Khasawneh and Dr. Saidur Rahman Chowdhury contributed to the survey, analysis, and write-up. Mr. Mohammed Nayeemuddin and Mr. Danish Ahmed contributed to the data collection and calculations. Dr Andi Asiz contributed to the survey and write-up. All authors approved the final version.

\section{ACKNOWLEDGMENTS}

Thanks are given to the ASCE Civil Engineering Club at PMU, which administered the survey questionnaire to the students in the department. Also, special thanks are given to the students of the CE department who participated in the survey.

\section{REFERENCES}

[1] M. Hassounah, H. Raheel, and M. Alhefzi, "Digital response during the COVID-19 pandemic in Saudi Arabia," Journal of Medical Internet Research, vol. 22, no. 9, 2020.

[2] G. Korkmaz and Ç. Toraman, "Are we ready for the post-COVID-19 educational practice? An investigation into what educators think as to online learning," International Journal of Technology in Education and Science, vol. 4, no. 4, pp. 293-309, 2020.

[3] I. A. Bogoslov and A. E. Lungu, "Facing the new learning normality Europe at a glance in the context of coronavirus pandemic," Revista Economica, vol. 72, no. 1, pp. 25-36, 2020.

[4] O. B. Adedoyin and E. Soykan. (2020). Covid-19 pandemic and online learning: The challenges and opportunities. Interactive Learning Environments. [Online]. Available: https://doi.org/10.1080/10494820.2020.1813180

[5] M. M. Alzahrani and S. S. Aljraiwi, "Effectiveness using Blackboard Collaborate tools in promoting practical skills among students of the foundation year in e-learning course," British Journal of Education, vol. 5, no. 4, pp. 19-53, 2017.

[6] M. W. Romaniuk and J. Łukasiewicz-Wieleba, "Crisis remote education at the Maria Grzegorzewska University during social isolation in the opinions of students," International Journal of Electronics and Telecommunications, vol. 66, no. 4, pp. 807-812, 2020.

[7] D. Sulisworo, A. Y. Astuti, and N. Fatimah, "Online learning implementation during COVID-19 mitigation in Indonesia: Measuring the lecturers' technology readiness," International Journal of Advanced Science and Technology, vol. 29, no. 7, pp. 2252-2263, 2020.

[8] T. Gonzalez, M. A. Rubia, K. P. Hincz, M. Comas-Lopez, L. Subirats, S. Fort, and G. M. Sacha, "Influence of COVID-19 confinement on students' performance in higher education," PLOS ONE, vol. 15, no. 10 2020.

[9] M. M. Abdeldayem, S. H. Aldulaimi, and M. L. A. Aldulaimi, "Virtual learning and students' connectedness in the time of coronavirus," International Journal of Advanced Science and Technology, vol. 29, no 5, pp. 12634-12645, 2020.

[10] L. K. Veni and N. C. V. Revanth, "A survey on impact of Covid 19 on UG\&PG students," International Journal of Creative Research Thoughts, vol. 8, no. 8, pp. 253-262, 2020.

[11] N. Almazova, E. Krylova, A. Rubtsova, and M. Odinokaya, "Challenges and opportunities for Russian higher education amid COVID-19: Teachers' perspective," Education Sciences, vol. 10, no. 12, p. 368, 2020.

[12] K. K. Naji, X. Du, F. Tarlochan, U. Ebead, M. A. Hasan, and A. K. Al-Ali, "Engineering students' readiness to transition to emergency online learning in response to COVID-19: Case of Qatar," EURASIA Journal of Mathematics, Science and Technology Education, vol. 16 , no. 10, pp. 1305-8223, 2020.

[13] L. A. Gelles, S. M. Lord, G. D. Hoople, D. A. Chen, and J. A. Mejia, "Compassionate flexibility and self-discipline: Student adaptation to emergency remote teaching in an integrated engineering energy course during COVID-19," Education Sciences, vol. 10, no. 11, p. 304, 2020.

[14] J. M. Rama, M. Sabasales, A. Antonio, C. Ricohermoso, J. Torres, A. Devanadera, C. Tulio, and E. Alieto, "Virtual teaching as the "new norm": Analyzing science teachers' attitude toward online teaching, technological competence and access," International Journal of Advanced Science and Technology, vol. 29, no. 7, pp. 12705-12715, 2020.

[15] N. Mahtab, "A shift to online learning in Bangladesh universities post pandemic effect of COVID 19: A blessing or curse?" International Journal of Advanced Science and Technology, vol. 29, no. 7s, pp. 4122-4127, 2020.

[16] N. N. Rose, A. S. Ishak, and N. Ahmad, "Covid-19 pandemic: Towards the "new normal" among Malaysian public universities," International Journal of Advanced Science and Technology, vol. 29, no. 4, pp. 2750-2758, 2020.

[17] P. Tarkar, "Impact of covid-19 pandemic on education system," International Journal of Advanced Science and Technology, vol. 29, no. 9, pp. 3812-3814, 2020.

[18] R. Anusha and A. Angayarkanni, "Predicting the student's preference between conventional learning and e-learning," International Journal of Advanced Science and Technology, vol. 29, no. 4, pp. 5917-5922, 2020.

[19] Ç. Erhan and Ş. Gümüş, "Opportunities and risks in higher education in the post pandemic period," Küresel Salginin Anatomisi: Insanve Toplumun Geleceği, TÜBA, 2020.

[20] R. Huang, A. Tlili, T. W. Chang, X. Zhang, F. Nascimbeni, and D. Burgos, "Disrupted classes, undisrupted learning during COVID-19 outbreak in China: Application of open educational practices and resources," Smart Learning Environments, vol. 7, no. 19, 2020.

[21] J. A. Manco-Chavez, Y. C. Uribe-Hernandez, R. Buendia-Aparcana, J. J. Vertiz-Osores, S. D. I. Alcoser, and R. A. Rengifo-Lozano, "Integration of ICTS and digital skills in times of the pandemic covid-19," International Journal of Higher Education, vol. 9, no. 9, pp. $11-20,2020$.

[22] A. Ożadowicz, "Modified blended learning in engineering higher education during the COVID-19 lockdown: Building automation courses case study," Education Sciences, vol. 10, no. 10, 2020.

[23] M. Padmaja and K. V. R. Reddy, "Online tools for strengthening remote teaching-learning in the times of emergencies: COVID-19," International Journal of Advanced Science and Technology, vol. 29, no. 7s, pp. 4150-4155, 2020.

[24] M. L. George, "Effective teaching and examination strategies for undergraduate learning during COVID-19 school restrictions," Journal of Educational Technology Systems, vol. 49, no. 1, pp. 23-48, 2020.

[25] S. Gregory and M. Bannister-Tyrrell, "Digital learner presence and online teaching tools: Higher cognitive requirements of online learners for effective learning," Research and Practice in Technology Enhanced Learning, vol. 12, no. 18, 2017.

[26] J. Valverde-Berrocoso, M. C. Garrido-Arroyo, C. Burgos-Videla, and M. B. Morales-Cevallos, "Trends in educational research about e-learning: A systematic literature review (2009-2018)," Sustainability, vol. 12, no. 5153, 2020.

[27] E. Galy, C. Downey, and J. Johnson, "The effect of using e-learning tools in online and campus-based classrooms on student performance," Journal of Information Technology Education, vol. 11, pp. 209-229, 2011.

[28] N. Kapilan, P. Vidhya, and X. Z. Gao, "Virtual laboratory: A boon to the mechanical engineering education during covid-19 pandemic," Higher Education for the Future, vol. 8, no. 1, pp. 1-16, 2020.

[29] J. Qadir and A. Al-Fuqaha, "A student primer on how to thrive in engineering education during and beyond COVID-19," Education Sciences, vol. 10, no. 9, p. 236, 2020.

[30] S. Nogales-Delgado, S. R. Suero, and J. M. E. Martín, "COVID-19 outbreak: Insights about teaching tasks in a chemical engineering laboratory," Education Sciences, vol. 10, no. 9, p. 226, 2020.

Copyright $\odot 2021$ by the authors. This is an open access article distributed under the Creative Commons Attribution License which permits unrestricted use, distribution, and reproduction in any medium, provided the original

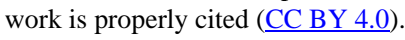

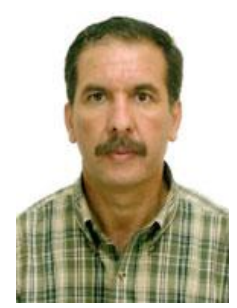

Tahar Ayadat is an associate professor of civil engineering at Prince Mohammad Bin Fahd University (PMU), Al Khobar, Saudi Arabia. He earned his PhD in civil engineering from Sheffield University, England, in 1991. His major expertise is in the area of geotechnical and geo-environmental engineering. Dr. Ayadat has about 30 years of academic and practical experience in conducting design, analysis, inspection, expertise, and management of various projects, such as domestic, commercial, and industrial construction; bridges, roads, and railways; dams; site rehabilitation; and more. He has published more than 
100 papers and technical reports in refereed journals, international conference proceedings, and the government and public domains.

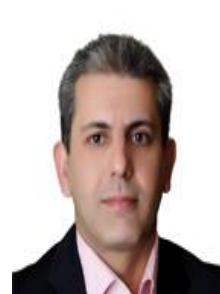

Mohammad Ali Khasawneh is an associate professor of civil engineering at Prince Mohammad Bin Fahd University (PMU), Kingdom of Saudi Arabia. Dr. Khasawneh earned his master of science and $\mathrm{PhD}$ in civil engineering from the University of Akron, Ohio, USA, in the years 2005 and 2008, respectively. He earned his bachelor's degree in civil engineering from Jordan University of Science and Technology (JUST) in 2003. He has published many scientific papers in refereed journals and international conference proceedings. Dr. Khasawneh was the recipient of the Best Thesis Award at JUST in 2018.

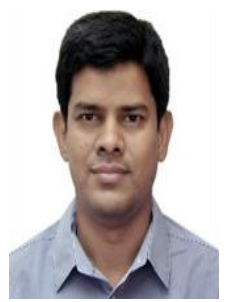

Saidur R. Chowdhury is an assistant professor in the civil engineering department at Prince Mohammad Bin Fahd University (PMU), Al Khobar, Saudi Arabia. He completed his $\mathrm{PhD}$ in environmental and geo-environmental engineering at Western University (UW) in Canada. He has published scientific papers in refereed journals and international conference proceedings, as well as technical reports for different environmental consulting companiess in Canada. UW acknowledged his research contribution by honoring him with the prestigious R.M. Quigley Award for Research Excellence in 2011.

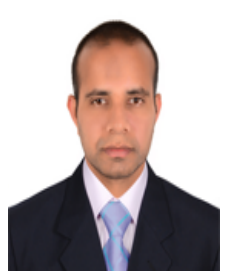

Mohammed Nayeemuddin is currently a lab instructor in the Civil Engineering Department at Prince Mohammad Bin Fahd University (PMU), Al Khobar, Saudi Arabia. His major expertise is in the seismic behavior of earthquake structures and the effects of fine aggregate replacement with class f fly ash on the mechanical properties of concrete. He completed his master of technology degree in structural engineering with civil specialization in 2012 and his bachelor of civil engineering in 2009 at Visveswaraya Technological University (VTU), Belgaum, Karnataka, India.

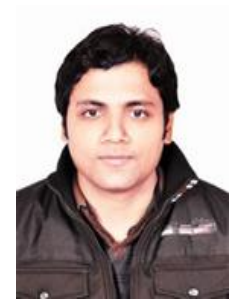

Danish Ahmed is currently a lab instructor in the Civil Engineering Department at Prince Mohammad Bin Fahd University (PMU), Al Khobar, Saudi Arabia. His major expertise is in the seismic testing of reinforced concrete structural members, retrofitting, and finite element modeling. He completed his master of science in civil engineering (structures) in 2012 at King Fahd University of Petroleum and Minerals, Saudi Arabia, and his bachelor of science in civil engineering in 2008 from Sir Syed University of Engineering and Technology, Pakistan. He has received a bronze medal and university scholarships for his outstanding academic performance.

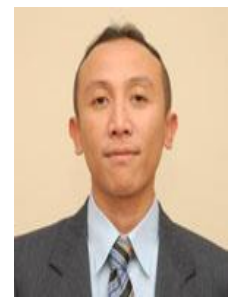

Andi Asiz is an associate professor and the chair of the Civil Engineering Department at Prince Mohammad Bin Fahd University (PMU), Al Khobar, Saudi Arabia. His major expertise is in the area of structural engineering and mechanics. He has more than 15 years of academic and practical experience in conducting analyses, designing, inspecting, and monitoring various engineered structures, ranging from reinforced concrete and steel buildings to pre-stressed concrete bridges to timber structures. He has published more than 50 papers and technical reports in refereed journals, international conference proceedings, and the government and public domains. 